and other pathogens on the host tissue. Studies are described in the realm of morphogenesis, and this isolation of tissues from the morphogenetic influences of neighbouring tissues will undoubtedly form the soundest approach to questions of the effects of growth substances, chemical gradients, and so on.

It cannot be doubted that the isolation and successful growth of tissues is of great promise in many fields of plant science, or that the study has now reached the stage at which rapid advances are to be expected. It seems, in fact, probable that only the difficulties, real and imagined, of the culture of plant tissues has prevented the use of this method in many problems which can scarcely be solved by any other means. This book does much to remove these difficulties by emphasizing the precautions to be taken and the pitfalls to avoid, and its service to science in this way alone can scarcely be estimated at this time.

The book is to be heartily recommended to all plant biologists interested in new developments as a volume which can be read with pleasure as well as profit. It is illustrated by numerous photographs of excellent quality (including portraits of the principal workers in the field of tissue culture), and the presentation is of high standard. R. D. Preston.

\section{ASPECTS OF REHABILITATION}

Rehabilitation of the War Injured

A Symposium. Edited by Dr. William Brown Doherty and Dr. Dagobert D. Runes. Pp. 684. (New York : Philosophical Library, Inc., 1943.) 10 dollars.

$\mathrm{D}$ URING the past few years, the word 'rehabilitation' has come into common usage, but there does not appear to be a clear definition of its exact significance. This doubt is evidently shared by the contributors to this symposium, and we are presented, therefore, with articles based on almost every shade of its meaning. This variation in interpretation carries us from excellent chapters on the creation and maintenance of physical and mental fitness in those who have suffered from extensive war injuries, down to much less excellent sections upon highly specialized surgery.

There may be justification for considering that surgical repair is necessarily part of rehabilitation; it may, indeed, be all that is necessary. On the other hand, rehabilitation may more urgently follow conditions which do not require preliminary operation. That great part of the book, therefore, which deals with the technique of reconstructive and plastic surgery would seem to refer chiefly to those patients in whom no serious after-treatment is of importance. Parts of this section fulfil no particular purpose. They are couched in vague terms and end by being neither a technical description which might be of surgical value, nor yet sufficiently free from detail to make them valuable for anyone whose interest is not primarily surgical. Worse still, the contributors of some of these chapters have not considered it desirable to keep within the elastic limits of such a title as the editors have chosen, and have diverged to describe the treatment of defects which have no relation to war or its sequelæ. It may be that the writers themselves are not to blame for this, as it appears from the extensive list of acknowledgments that a great deal of the material has been collected from already published sources. This may also account for the very marked lack of clarity in the illustrations.
It should not be supposed, however, that this adverse criticism is applicable to the whole symposium. Many of the sections are concerned with specialized after-treatment which is rendered necessary by reason of some particular injury-the loss of sight, of hearing, or of a limb. Others deal fully with the specialized aspects of such treatment, and naturally enough the amount of stress laid on any particular method is in direct relation to the enthusiasm of its exponent.

The multiplicity and diversity of the views expressed are but an index of the magnitude of the problem, and one cannot help feeling that even if this volume does not answer the questions it raises, it should do much to stimulate coherent thought upon a subject which is, at the moment, only vaguely appreciated. In other words, when rehabilitation ceases to be a political catchphrase and is returned to the specialists who practise its component sections, we may well look forward to a great improvement in both the degree and duration of disability from which an injured man may suffer.

If this book is intended for the general public, it will, in the reviewer's opinion, leave them interested but somewhat confused. If, on the other hand, it is directed towards the medical profession, it should go far towards convincing them that the solution of the problem lies almost entirely in the integration of their various efforts into one harmonious whole.

\section{SYMPOSIUM ON CANCER}

Selected Papers from the Royal Cancer Hospital (Free) and the Chester Beatty Research Institute Published by order of the Governors of the Royal Cancer Hospital (Free), London. Vol. 2. Pp. viii+414. (London : Royal Cancer Hospital (Free), 1943.) 16.

TWENTY-SEVEN authors contribute to this I symposium, which will be welcomed by all who have to deal with any aspect of cancer. The papers, some of which are highly technical, are reprinted from many journals and form four main groups : three of general clinical interest; four on radiation therapy ; eight on calculations and physical measurements of radiation; eighteen on experimental research, and a review of the world literature 1938-1939 on chemical compounds as carcinogenic agents. The latter paper, by Profs. Cook and Kennaway, follows an earlier review on the same subject and is a masterly piece of work, including a bibliography of some five hundred new references. About half the volume is concermed with the synthesis and testing of chemical carcinogens and growth inbibitors. It is not yet certain that any of these substances are directly related to human cancer other than industrial cancer. A careful perusal of the results shows that many new facts could not have been established by studying only the earliest and best-known carcinogenic hydrocarbons. To the reviewer, the most interesting new experiments are those dealing with growth-inhibiting hydrocarbons that are not necessarily carcinogenic ; with carcinogens that act on remote organs as well as locally; with those that show the need for more than one kind of biological test before a substance can be regarded as non-carcinogenic; and, particularly, with the extraction from human livers (not necessarily from cancer subjects) of unidentified carcinogens.

The scientific world owes much to this team and to the guiding influence of Prof. Kennaway, who was the first to prove that cancer could be induced by a hydrocarbon.

P. R. Peacock. 